\title{
A I nformática Na Educação: Como, Para Que e Por Que
}

Autores:J osé A. Valente

Afiliação:Departamento de Multimeios e Nied - Universidade Estadual de Campinas - Unicamp, Campinas - SP javalente@unicamp.br

\section{Introdução}

O objetivo desse artigo é responder a três perguntas básicas sobre o uso do computador na educação: como ele pode ser usado, para que deve ser usado e por que o computador deve ser usado na educação.

O computador pode ser usado na educação tanto para ensinar sobre computação - ensino de computação quanto para ensinar praticamente qualquer assunto - ensino por intermédio do computador.

No ensino de computação o aluno usa o computador para adquirir conceitos computacionais, como princípios de funcionamento do computador, noções de programação e implicações sociais do computador na sociedade. Esta abordagem tem sido bastante divulgada e é a solução que muitas escolas encontram para o uso do computador. Assim, o atual currículo é incrementado com uma disciplina de "Introdução à Informática" cujo objetivo é ensinar sobre computação. Certamente isto permitirá ao aluno conhecer o computador. Porém, do ponto de vista educacional, o computador pode oferecer muito mais.

O computador pode ser parte integrante do processo de ensino-aprendizagem de qualquer disciplina curricular. Isto significa que o computador pode ser usado nas disciplinas já existentes permitindo a "manipulação" de conceitos e estratégias de usos destes conceitos na resolução de problemas ou projetos. Neste caso, existem diversas abordagens sobre como isso pode ser feito. Estas diferentes abordagens consideram diferentes funções para o computador bem como para justificar o seu uso. A discussão sobre estes diferentes funções é o objeto deste artigo.

\section{Como o Computador Pode Ser Usado na Educação?}

O computador pode ser usado no processo ensino-aprendizagem, praticamente, de qualquer disciplina ou domínio do conhecimento. Entretanto, a abordagem pedagógica de como isto acontece é bastante variada, oscilando entre dois grandes pólos.

Estes polos são caracterizados pelos mesmos ingredientes: computadores (hardware), o software (o programa de computador que permite a interação homem-computador) e o aluno. Porém, o que estabelece a polaridade é a maneira como estes ingredientes são usados. Em um lado, o computador, por intermédio de um software educacional, ensina o aluno. Enquanto no outro, o aluno, por intermédio de um software aberto, "ensina" o computador.

Quando o computador ensina o aluno, o computador assume o papel de máquina de ensinar e a abordagem pedagógica é a instrução auxiliada por computador, ou seja, o instrucionismo. Esta abordagem tem suas raízes nos métodos tradicionais de ensino, porém em vez da folha de instrução ou do livro de instrução, é usado o computador. Os software que implementam esta abordagem são os tutoriais, os software de exercício-e-prática e os jogos. Os tutoriais enfatizam a apresentação das lições ou a explicitação da informação. No exercício-e-prática a ênfase está no processo de ensino baseado na realização de exercícios com grau de dificuldade variado. Nos jogos educacionais a abordagem pedagógica utilizada é a exploração livre e o lúdico em vez da instrução explícita e direta. 
Quando o aluno "ensina" o computador, o computador passa a ser uma máquina para ser ensinada, propiciando condições para o aluno construir o seu conhecimento. A abordagem pedagógica utilizada é o construcionismo. Nesse caso, o software são abertos, de uso geral, como as linguagens computacionais, como BASIC, Pascal, Logo ou, linguagens para criação de banco de dados ou processadores de texto. Em todos esses casos, o aluno pode representar suas idéias por meio destes software, ou seja, o computador pode ser visto como uma ferramenta que permite ao aluno resolver problemas ou realizar tarefas como desenhar, escrever etc.

Os software do tipo simulação oferecem ao aluno a possibilidade de desenvolver hipóteses, testá-las, analisar resultados e refinar os conceitos. As simulações podem ser agregadas tanto a um polo quanto ao outro, dependendo do grau de abertura que elas oferecem. Na simulação fechada o aluno não tem meios de interferir no fenômeno que está sendo simulado. Neste caso, o computador mostra como um determinado fenômeno se comporta e o aluno praticamente assiste a essa demonstração. Assim, a simulação fechada pode ser caracterizada como um software que ensina e deve ser agregada ao polo instrucionista. A simulação aberta permite ao aluno "ensinar" ou passar para o software as leis que regem o fenômeno que está sendo simulado. Neste caso, a simulação aberta deve ser agregada ao polo construcionista, ou seja ao pólo dos software que permitem ao aluno ensinar a máquina.

\section{Para que o Computador na Educação?}

Nos pólos instrucionista e construcionista o computador assume funções bastante distintas.

O instrucionismo pode ser visto como a informatização dos métodos de ensino tradicionais e o computador tem a função de "entregar" a informação: alguém implementa no computador uma série de informações que devem ser passadas ao aluno na forma de um tutorial, exercício-e-prática ou jogo. Neste caso, o computador é usado para passar informação para o aluno .I sto é feito como que se o conhecimento fosse tijolos que devem ser justapostos e sobrepostos na construção de uma parede. O computador tem a finalidade de facilitar a construção desta "parede", fornecendo "tijolos" de tamanhos adequados, em pequenas doses e de acordo com a capacidade individual de cada aluno.

Já, no construcionismo, o computador requer certas ações que são bastante efetivas no processo de construção do conhecimento. Para "ensinar" o computador o aluno deve utilizar conteúdos e estratégias. No caso da resolução de um problema via computador o aluno tem que combinar estes conteúdos e estratégias em um programa que resolve este problema. A análise da tarefa de programar o computador tem permitido identificar diversos passos que o usuário realiza e que são de extrema importância na aquisição de novos conhecimentos (Valente, 1999). Primeiro, a interação com o computador na programação requer a descrição de uma idéia em termos de uma linguagem formal e precisa. Esta descrição permite ao aluno representar e explicitar o nível de compreensão que possui sobre os diferentes aspectos envolvidos na resolução do problema. Segundo, o computador executa fielmente a descrição, fornecendo uma resposta imediata e desprovida de qualquer animosidade ou afetividade que possa haver entre o aluno e o computador. 0 resultado obtido é fruto somente do que foi solicitado à máquina. Terceiro, o resultado obtido serve como objeto de reflexão sobre o que foi solicitado ao computador. Finalmente, se o resultado não corresponde ao que era esperado, o aluno tem que depurar a idéia original, adquirindo novos conteúdos ou estratégias[1].

Portanto, na atividade de programação do computador acontece por meio de um ciclo descrição-execuçãoreflexão-depuração-descrição. Este ciclo não só contribui para a resolução do problema como para criar condições para o aluno construir novos conhecimentos.

Entretanto, este ciclo não acontece simplesmente colocando o aluno frente ao computador. A interação alunocomputador precisa ser mediada por um profissional que entenda a aprendizagem como um processo de construção do conhecimento. Ele tem que interagir com o aluno procurando compreender suas idéias para saber intervir apropriadamente na situação de modo a contribuir no processo de construção de conhecimento por parte do aluno[2] (Valente, 1996).

Além disso, o aluno como um ser social, está inserido em um ambiente constituído, localmente, pelo seus colegas e, globalmente, pelos pais, amigos e a sua comunidade. O aluno pode usar todos esses elementos sociais como fonte de idéias, de conhecimento ou mesmo de problemas contextuais para serem resolvidos como Paulo Freire sugere[3] (Freire, 1975). 
A interação do aprendiz com o computador e os diversos elementos que estão presentes na atividade de programação, são mostrados no esquema:

Figura 2 -Ciclo descrição-execução-reflexão-depuração-descrição que se estabalece na atividade de programação

Assim, quando perguntamos "para que usar computadores na educação?" a resposta mais provável é o fato de estarmos interessados em explorar as características dos computadores que contribuem para o processo de conceituação ou construção do conhecimento. Estas características incluem a expressão do que o aprendiz está pensando em termos de uma linguagem formal e precisa, a execução do que ele está pensando em termos de resultados fieis e imediatos. Elas estão presentes nas atividades de programação e auxiliam o aprendiz a alcançar a fase de compreensão de conceitos. Ele pode refletir sobre os resultados de suas ações e idéias e esta reflexão é o mecanismo pelo qual o aprendiz se torna consciente de seu conhecimento e, assim, pode transformar seus esquemas mentais em operações e noções mais complexas.

Embora seja fácil entender como se dá o processo de construção do conhecimento no caso da programação, esse processo pode acontecer também quando o aprendiz utiliza outros software como processador de texto ou sistemas de autoria. A diferença da programação para esses outros usos é o quanto esses outros software oferecem em termos de facilidade para a realização do ciclo descrição-execução-reflexão-depuração-descrição (Valente, 1999).

\section{Por que o Computador na Educação?}

Entre as abordagens instrucionista e construcionista, certamente, o computador pode ser usado de maneira muito mais efetiva se utilizado segundo o construcionismo. No caso do instrucionismo temos a informatização do processo de ensino tradicional. No caso do construcionismo o computador é usado para implementar o ciclo descrição-execução-reflexão-depuração-descrição permitindo ao aluno construir o conhecimento e, portanto, aprender.

A possibilidade que o computador oferece para o aluno aprender, em vez de ser ensinado, constitui uma verdadeira transformação do processo educacional. O ensino tradicional ou a informatização do ensino tradicional é baseado na transmissão de informação, onde ainda existe o professor ou o computador, proprietário do saber, que assume que o aluno é um recipiente que deve ser preenchido. O resultado desta abordagem é o aluno passivo, sem capacidade crítica e com uma visão de mundo segundo a que Ihe foi transmitida. Esse aluno, quando formado, terá pouca chance de sobreviver na sociedade do conhecimento. Na verdade, tanto o ensino tradicional quanto a informatização desse ensino prepara um profissional obsoleto.

A sociedade do conhecimento exigirá um profissional crítico, criativo, com capacidade de pensar, de aprender a aprender, trabalhar em grupo e de conhecer o seu potencial intelectual. Este profissional deverá ter uma visão geral sobre os diferentes problemas que afligem a humanidade, como os sociais e os ecológicos, além de profundo conhecimento sobre domínios específicos. Em outras palavras, um sujeito atento e sensível às mudanças da sociedade, com uma visão transdisciplinar e com capacidade de constante aprimoramento e 
depuração de idéias e ações.

Certamente, essa nova atitude é fruto de um processo educacional, cujo objetivo é a criação de ambientes de aprendizagem onde o aluno possa vivenciar e desenvolver essas habilidades. Elas não são passíveis de serem transmitidas mas devem ser construídas e desenvolvidas por cada indivíduo.

Os computadores devem estar inseridos nestes ambientes de aprendizagem possibilitando a construção de conceitos e o desenvolvimento de habilidades necessárias para a sobrevivência na sociedade do conhecimento. O aprendizado de um determinado conceito deve ser construído pelo aluno por meio do desenvolvimento de projetos que tenham um caracter interdisciplinar onde o computador é usado como fonte de informação e recurso para resolução de problemas, como propõe a abordagem construcionista.

A implementação de projetos propicia ao aluno a possibilidade de aprender a buscar as informações necessárias para a implementação dos mesmos (aprender a aprender); de ser crítico em relação aos resultados obtidos; de desenvolver a noção de depuração de idéias como o motor propulsor da aprendizagem; e de estabelecer relações entre diferentes conteúdos disciplinares. O aluno, acaba por adquirir habilidades e valores da sociedade do conhecimento porque as vivencia e, não, porque elas são transmitidas ao aluno.

A aprendizagem baseada em projetos significa a existência de diversos níveis de complexidade, integrados e coerentes:

a) Projeto da escola. Proposta pedagógica de como a escola pretende trabalhar as questões relativas ao processo ensino-aprendizagem, podendo ou não prever a utilização do computador;

b) Projeto da disciplina. Proposta de como cada disciplina, com base no projeto da escola, pretende desenvolver os conteúdos disciplinares, podendo ou não estar utilizando os recursos da informática;

c) Projeto do aluno. Projeto que o aluno escolhe e desenvolve, com base no projeto da disciplina integrando o uso da informática e conteúdos de outras disciplinas.

Assim, o computador usado segundo a abordagem construcionista, tem a finalidade de implementar um processo de aprendizagem baseado em projetos e preparar o aluno para a sociedade do conhecimento. Ele deve ser uma ferramenta de transformação da educação e não um meio de informatizar um processo educacional já obsoleto.

\section{Referências Bibliográficas}

1. Carraher, T.N. (1983). O Método Clínico: usando os exames de Piaget. Petrópolis: Editora Vozes.

2. Freire, P. (1975). Pedagogia do Oprimido. Rio de Janeiro: Paz e Terra.

3. Secretaria Municipal de Educação de São Paulo (1992). Projeto Gênese - A Informática Chega ao Aluno da Escola Pública Municipal. Relatório Técnico. São Paulo: Prefeitura do Município de São Paulo.

4. Valente, J. A. (Org.) (1996). O Professor no Ambiente Logo: formação e atuação. Campinas: NiedUnicamp.

5. Valente, J .A. (Org.) (1999). O Computador na Sociedade do Conhecimento. Campinas: Nied-Unicamp.

6. Valente, J. A (1992). Logo and Freire's Educational Paradigm. Logo Exchange, 11(1):39-43.

7. Vygotsky, L.S. (1978). Mind in Society: the development of higher psychological processes. Cambridge, Mass.: Harvard University Press. 
descrição das idéias do aluno em termos de uma linguagem precisa e formal. Além disso, existe uma correspondência direta entre cada comando e o comportamento do computador. Essas caraterísticas disponíveis no processo de programação facilitam a análise do programa de modo que o aluno possa achar seus erros (bugs). O processo de achar e corrigir o erro constitui uma oportunidade única para o aluno aprender sobre um determinado conceito envolvido na solução do problema ou sobre estratégias de resolução de problemas. O aluno pode experimentar alterar o conteúdo ou as estratégias e verificar se essas alterações são mais ou menos efetivas na busca da solução do problema. O aluno pode também usar seu programa para relacioná-lo com seu pensamento em um nível metacognitivo. Ele pode analisar seu programa em termos da efetividade das idéias, estratégias e estilo de resolução de problema. Nesse caso, o aluno começa a pensar sobre suas próprias idéias.

[2]0 modelo que melhor descreve o papel do professor no ambiente de programação é a função que combina o método clínico piagetiano, que permite ao professor entender o que o aluno está pensando (Carraher, 1983) e a intervenção do professor segundo a Zona de Desenvolvimento Proximal (ZPD), definida por Vygotsky como "a distância entre o nível de desenvolvimento real, determinado através da solução independente de problemas, e o nível de desenvolvimento potencial, determinado através da solução de problemas sob a orientação de um adulto ou em colaboração com colegas mais capazes" (Vygotsky, 1978, p. 86).

[3]0 aluno pode aprender com a comunidade, bem como, auxiliar a comunidade a identificar problemas, resolvê-los por meio do computador e apresentar a solução para a comunidade. Esta abordagem foi utilizada no Projeto Gênese, sobre o uso do computador na educação, desenvolvido pela Secretaria de Educação do Município de São Paulo (Valente, 1992; Secretaria Municipal de Educação de São Paulo, 1992). 